\title{
MODERNIZACIÓN REGIONAL Y CENTRALIDAD EN EL CASO DE GUAMÚCHIL, SINALOA, MÉXICO (1940-1960)
}

\author{
REGIONAL MODERNIZATION AND CENTRALITY \\ IN THE CASE OF GUAMUCHIL, SINALOA, MEXICO \\ (1940-1960)
}

\author{
Jesús Rafael Chávez Rodríguez \\ Eduardo Frías Sarmiento \\ Universidad Autónoma de Sinaloa, Sinaloa, México \\ rafachavez7@hotmail.com; eduardofrias@uas.edu.mx
}

\begin{abstract}
Resumen. Este artículo analiza un periodo de dos décadas que representa el crecimiento inicial de la ciudad de Guamúchil, población ubicada en la región del Évora, en la zona agrícola del estado de Sinaloa en el noroeste mexicano. Durante las dos décadas que transcurrieron desde 1940 hasta 1960, Guamúchil adquiere centralidad dentro de la región debido a los efectos modernizadores de su zona de influencia, lo que permite mayores niveles de producción y diversificación de cultivos. Lo anterior propició que las actividades económicas y sociales se concentraran en un punto específico de la región: la ciudad de Guamúchil, un sitio que no termina de definirse como rural o urbano.
\end{abstract}

Palabras clave: región; rural; urbano; modernización; centralidad.

Abstract. This article analyzes a period of two decades that represents the initial growth of the city of Guamuchil, a built-up area in the Evora region, in the agrarian zone of the state of Sinaloa in the north west of Mexico. During the two decades that elapsed between 1940 and 1960, Guamuchil acquired importance in the region due to the modernizing effects of its area of influence, permitting higher production levels and crop diversification. This brought about the concentration of economic and social activities in a specific point in the region: the city of Guamuchil, a location that cannot be classified as either entirely rural or urban.

Key words: region; rural; urban; modernization; centrality.

Fecha de recepción: 4 de noviembre de 2015. Fecha de aceptación: 16 de enero de 2016.

Am. Lat. Hist. Econ., sep.-dic., 2016, pp. 174-203 | DOI: 10.18232/ALHE.v23I3.721 


\section{INTRODUCCIÓN}

$\mathrm{E}$ n los albores del siglo Xx, Mocorito era la población de mayor importancia en el espacio de la denominada región del Évora. ${ }^{1}$ Sin embargo, esta villa fue desplazada como centro económico en las primeras décadas de dicho siglo, pasando a ocupar su lugar la pequeña población llamada Guamúchil (véase mapa 1).

El periodo que analizaremos puede considerarse como la base del despegue de un nuevo centro económico en la región del Évora, cuya dinámica responde a un periodo de crecimiento económico y demográfico sostenido en el ámbito nacional bajo el modelo de sustitución de importaciones (Ibarra, 1993, p. 87). Periodo, también, en el que la zona agrícola sinaloense experimentó efectos muy visibles de modernización, ${ }^{2}$ reflejado en la construcción de nuevas vías de comunicación, ampliación de la infraestructura de riego para el desarrollo agrícola y en la concentración de las actividades económicas en nuevos espacios.

En este sentido, modernización y centralidad constituyen conceptos clave para entender el fenómeno de cambio en espacios de dimensiones muy localizadas de la región en estudio. La modernización, como lo propone Berman (1988), se gesta desde el siglo XIX con un paisaje sumamente desarrollado, diferenciado y dinámico, ${ }^{3}$ asociado con la idea de progreso, de cambio y de ruptura con el atraso. Esta conceptualización guarda diferencias para América Latina, pues a juicio de Marín y Morales (2010) la modernización ha tenido dos caminos conectados entre sí; por un lado, estaría el camino de la modernización económica y, por el otro, estaría el camino de la modernización política y cultural, de las que la económica y los asuntos que implican su desarrollo han sido mayormente privilegiadas.

Por su parte, la teoría del lugar central propuesta por Christaller (1966), de carácter eminentemente regional, ha sido de utilidad para establecer el

\footnotetext{
${ }^{1}$ Se le denomina región del Évora a la zona ubicada en el centro-norte del estado de Sinaloa, sobre el delta del río Évora o Mocorito (cuenca). En ella se encuentran actualmente tres municipios: Mocorito, Angostura y Salvador Alvarado. Estos municipios fueron erigidos a partir de la segunda década del siglo XX como efectos de la revolución mexicana de 1910. Del distrito de Mocorito surgió el municipio libre de Mocorito en 1915; en 1916 se erigió la municipalidad de Angostura que había pertenecido al de Mocorito y en 1962 se erigió el municipio de Salvador Alvarado también desprendiéndose de Mocorito, cuya cabecera ocupó Guamúchil.

${ }^{2}$ Menciona Ibarra (1993) que con la modernización del periodo en México hubo consecuencias negativas, pues se generó un esquema de bipolaridad entre un sector moderno basado en el riego y el cultivo altamente rentable y un sistema tradicional, sobre todo en las tierras de temporal (p. 87).

${ }^{3}$ Berman (1988) entiende el concepto de modernización bajo un panorama dominado por las máquinas de vapor, fábricas, vías férreas, nuevas y muy vastas zonas industriales; ciudades que crecen de la noche a la mañana; con medios de comunicación que informan cada vez más a escala más amplia; con un mercado mundial siempre en expansión.
} 


\section{MAPA 1. UBICACIÓN DE LA REGIÓN DEL ÉVORA Y SUS PRINCIPALES POBLACIONES EN SINALOA, MÉXICO}

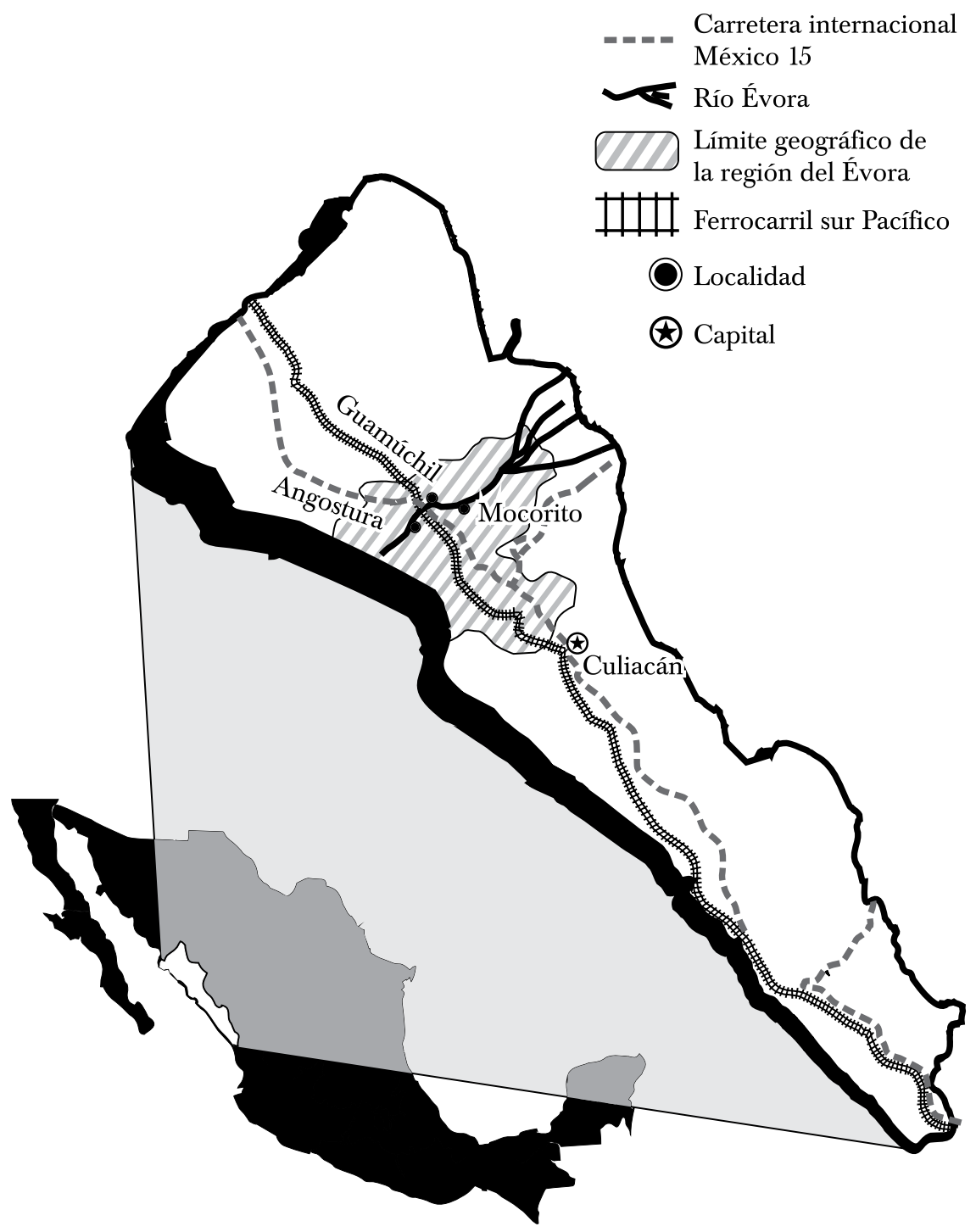

Fuente: elaborado por Jesús Rafael Chávez Rodríguez y Roberto Pérez Araujo. 
concepto de centralidad, pues pretende explicar el número, distribución espacial y el tamaño de los asentamientos a partir de la lógica de localización de las actividades terciarias; asimismo, bajo la flexibilidad de dicha teoría se pueden entender también los contextos interurbanos para explicar la organización espacial de las actividades comerciales en las ciudades. Según dicha teoría, estas actuarán como centros proveedores de bienes y servicios de sus regiones circundantes o hinterland, por lo que el concepto de centralidad toma importancia, pues quedará definido como la intensidad con la que una ciudad sirve a su región como proveedora de bienes y servicios, pues una ciudad será más central, en tanto ofrezca más bienes y servicios a su región circundante (Garrocho, 2012, p. 20).

En el estudio del presente caso, la modernización vial y la construcción de nuevos caminos hacia los valles agrícolas fueron elementos determinantes para la centralización de Guamúchil, ya que Mocorito y las comunidades situadas en su zona de influencia hacia los altos presentaron signos de aislamiento, pues las actividades económicas se enfilaron hacia los valles. En contraste, se acentuó el desarrollo de la agricultura en el valle de Angostura, donde se encontraba un número considerable de comunidades dispersas de pequeñas dimensiones y de carácter eminentemente agrícola, que confluían hacia Guamúchil, punto de embarque de la agricultura y otros productos de índole regional.

\section{TrANSFORMACIONES ECONÓMICAS Y SOCIALES EN MÉXICO y SinAlOA}

Una de las principales iniciativas del gobierno posrevolucionario fue el restablecimiento del orden económico nacional. Esto fue posible medianamente durante la década de 1920 y 1930 cuando apenas se colocaban las bases institucionales para promover la industrialización en el país y para impulsar la agricultura moderna en el estado de Sinaloa.

Ya entrada la década de 1940 se habían dejado atrás las ideologías de los gobiernos de la revolución mexicana y la decisión de industrializar el país a través de la sustitución de importaciones, ${ }^{4}$ y según afirman Aguilar y Meyer (1997, p. 192), se desplazó el centro de gravedad en el país; la sociedad se movió del campo a la ciudad. Dicho proyecto industrializador coincidió con la segunda guerra mundial, y a partir de 1942 las exportaciones de materias primas crecieron notablemente, lo que propició que el

\footnotetext{
${ }^{4}$ Según afirma Garza (2003) "posteriormente al fortalecerse los grupos políticos en el poder a partir de 1940, se diseña una estrategia para promover el crecimiento vía sustitución de importaciones de bienes de consumo e intermedios, así como el fomento a la agricultura comercial” (p. 49), a este último correspondió el caso de Sinaloa.
} 
país pudiera contar con las divisas necesarias para importar el equipo que necesitaba en sus industrias. Por ello, el impulso industrializador en México tendría lugar hasta después de la guerra.

Fue en este periodo cuando la agricultura sinaloense para la exportación experimentó una modernización derivada de los siguientes factores: mayor apoyo del Estado mediante cambios institucionales como la conformación de las Asociaciones de Agricultores, uso racional de los factores de producción, transformación de las empresas agrícolas capitalistas, aumento de la productividad por la introducción de nueva tecnología, mejoramiento y modernización de los canales de comercialización. Todo esto permitió concentrar la actividad agrícola de exportación en lugares que tuvieran centros de embarque hacia el exterior y a su vez al mercado interno para los productos regionales (Ibarra, 1993, p. 87).

La segunda guerra mundial fue un factor exógeno que favoreció la exportación de productos sinaloenses. Dicho fenómeno global causó grandes cambios en la economía del orbe y del estado; por ejemplo, incrementó el poderío de algunos mercados extranjeros como el de Estados Unidos, en el cual los empresarios sinaloenses colocaban una amplia gama de legumbres y hortalizas, especialmente el tomate de exportación.

En este sentido, un factor determinante para el desarrollo agrícola del estado de Sinaloa fue la modernización de la infraestructura de riego de amplias dimensiones. Por ejemplo, en el cardenismo se inició la construcción de la primera presa de almacenamiento en la entidad, que se inauguró en 1948, recibiendo por nombre Sanalona; esta fue determinante en el auge del sector primario de la entidad. En la década de 1940, con la entrada del nuevo gobierno federal, se delinearon nuevas políticas hidráulicas que beneficiaban en gran manera a los empresarios agrícolas ubicados en los valles de Culiacán y El Fuerte, que se convirtieron en las regiones de mayor desarrollo agrícola del estado en el centro y el norte, respectivamente. Aunado al incremento de la superficie irrigada, la agricultura del estado vivió la maquinización del campo de 1940 a 1960 (Morales, 2007, p. 271), periodo de crecimiento y desarrollo de la agricultura capitalista ${ }^{5}$ en Sinaloa.

Esta modernización del campo sinaloense tuvo como efecto la concentración de población y actividades económicas en algunos puntos localizados de los valles agrícolas, como fue el caso de Culiacán, que según el VI Censo de Población contaba con 22025 habitantes (Dirección General de

\footnotetext{
${ }^{5}$ La referencia "agricultura capitalista" se entiende en la lógica de las condiciones de explotación de la tierra, ya que la propiedad social o individual se insertan en una dinámica de producción intensiva en capital, altamente tecnificada y con mano de obra asalariada, cuya producción es orientada para el mercado más que para la subsistencia.
} 
Estadística/Secretaría de la Economía Nacional, 1948), mientras que para la siguiente década dobló la cifra a 48936 habitantes.

El desarrollo de las obras hidráulicas en la región del Évora fue importante para poblaciones de rango intermedio como Guamúchil. ${ }^{6}$ Aunque en este valle se presentó un evidente desarrollo agrícola, impulsado en un primer momento gracias a los canales construidos por medio de la iniciativa privada, el crecimiento más significativo fue a partir de la construcción de la presa Adolfo López Mateos (Culiacán), lo que coadyuvó a la ampliación del distrito de riego diez. Con la construcción de dicha presa, el riego se expandió del municipio de Culiacán hacia el norte del estado, beneficiando a los municipios de Mocorito y Angostura. De esta manera, se anexaron 90000 hectáreas a las 95000 ya existentes en 1957 dentro del distrito de riego, de las que 46000 se encontraban ubicadas en la zona cercana a Pericos y 44000 en el valle de Guamúchil y Angostura (Carrillo, 2013, p. 71; Zamudio, 2009).

\section{ACTIVIDADES ECONÓMICAS PREDOMINANTES EN LA REGIÓN DEL ÉVORA}

Una parte importante del desarrollo de Sinaloa y de su especialización agrícola en el siglo XX se sustentó en la modernización de la infraestructura hidráulica y en la construcción de nuevas vías de comunicación; sin embargo, existe una realidad contrastante, ya que la modernización de las ciudades más importantes del espacio sinaloense quedó desprovisto de un desarrollo social y urbano. Este es el periodo que marca el inicio del desequilibrio entre el desarrollo regional y local, pues se emprendió la construcción de infraestructura en los valles agrícolas, mientras que el desarrollo urbano de las ciudades tuvo que aguardar mejores tiempos.

\section{Actividad agrícola regional: diversificación de cultivos}

El desarrollo de la región del Évora inició su despegue a principios de la década de 1920 hasta la de 1930, bajo el influjo de la producción garbancera como elemento fundamental de su economía. Empero, el panorama de auge cambió debido a la falta de mercado para la comercialización del producto. Esto provocó que para la cosecha de 1938-1939, los agricultores

\footnotetext{
${ }^{6}$ Carrillo (2013, pp. 67-71) afirma que al final de la década de los cincuenta se inició la construcción de la presa denominada Adolfo López Mateos sobre el río Humaya, dentro del municipio de Culiacán, con la cual se beneficiaron las tierras de ese valle, pero además las de las zonas agrícolas de Pericos, Angostura y Guamúchil, ubicadas hacia el norte del Culiacán.
} 
suspendieran las siembras de la temporada siguiente. El estado de guerra en el que se encontraban algunos países europeos, especialmente la guerra civil española, causó una disminución, al grado de suspender la importación del garbanzo mexicano. Por su parte, las semillas oleaginosas como el ajonjolí, algodón, linaza y cacahuate registraban una considerable alza en sus precios y buenos rendimientos convirtiéndose en nuevas opciones de cultivo regional.

La diversificación de los cultivos permitió continuar en la carrera por nuevos centros de comercio, tanto internacionales como internos, pues "en el contexto nacional, el crecimiento de la industria, de la población y las ciudades así como la elevación del mercado interno conformaron una nueva demanda de la producción agrícola que fue aprovechada por Sinaloa” (Ibarra, 1993, p. 88).

De esta manera, la agricultura constituyó la actividad dominante en Sinaloa, y el ferrocarril fue el bastión para las exportaciones de la cada vez más variada producción. Los camiones de carga como una nueva forma de transporte moderno, lejos de ser férreos competidores del ferrocarril, se convirtieron en complemento de este, ya que conducían los productos hasta las estaciones del ferrocarril, donde depositaban las semillas en sus furgones.

Aunque se modernizó la infraestructura de caminos en Sinaloa, no se prescindieron problemas causados por los fenómenos naturales cuyos efectos escapaban de la acción humana. Algunas pérdidas registradas tuvieron lugar durante la temporada de legumbres de exportación comprendida de noviembre de 1944 a mayo de 1945. Los cultivos dañados fueron de tomate, chile, chícharo y mixtos en un espacio de alrededor de 25000 hectáreas, sumándose a ello las dificultades y deficiencias que se originaron por la escasez de carros refrigerados en las líneas del ferrocarril Sur Pacífico de México, que también había sido víctima del mal tiempo (Cruz, 1944). En los siguientes años, se restableció la infraestructura y se continuó con la siembra de los productos mencionados además del tradicional que era el garbanzo.

Al respecto, el cultivo del garbanzo en la región tuvo un repunte para 1947, cosa que no sucedía desde finales de la década de 1930 debido a los conflictos internos presentados en España. ${ }^{7}$ Para 1948 la superficie en la que se sembró garbanzo en Sinaloa fue de 32566 hectáreas que rindieron 40255 toneladas, de las cuales 33000 fueron de exportación (Macías,

${ }^{7}$ Puede verse en el informe de gobierno de Pablo E. Macías Valenzuela (1948) que la cantidad cosechada en ese año fue de 33000 toneladas (660 000 sacos de 50 kilos) y fue vendida a la Exportadora de Garbanzo, S. A. y a la Compañía Agrícola y Comercial del Noroeste, S. A. De esa cosecha se vendió el saco de 100 kilogramos a razón de 17.65 dólares, obteniendo los vendedores 5824500 dólares por ese concepto. 
1948), es decir, $82.5 \%$ salía a mercados externos, teniendo como mercado natural el de España. ${ }^{8}$ Durante el periodo de gobierno de Franco en este país, y con la disputa de ideologías que México había heredado del periodo cardenista, la tendencia era a cerrar las relaciones comerciales entre ambos, situación que afectaba el intercambio de mercancías, en especial del garbanzo que se producía en Sinaloa y que por esta razón se encontraban almacenadas (El Regional, 8 de junio de 1950). Pero estas circunstancias fueron las que forzaron para que se emprendiera la búsqueda de nuevos mercados para dicho producto, sin limitarse solamente al tradicional de España.

Por tales razones surgieron iniciativas para vender el garbanzo en el mercado estadunidense a través de Ludry Food Products Co. de Portland, que solicitó algunas muestras de diversas calidades del producto para lanzarlo al mercado de manera enlatada (El Regional, 8 de junio de 1950). También se exportó a otros países, como lo manifiesta un directorio comercial de la época: en Santiago de Cuba se vendieron 1000 toneladas de garbanzo que se desplazaron por el puerto de Mazatlán; en La Habana, Cuba, se vendieron 2000 toneladas, por el mismo puerto; en Puerto Rico y Nueva York se vendieron a una firma americana 1250 toneladas. Además, a San Francisco y Los Ángeles, California, fueron enviadas 250 toneladas (Directorio agrícola, comercial, industrial y profesional del estado de Sinaloa, 1957, p. 341).

El garbanzo producido en la región había sido considerado un producto destinado casi por completo a la exportación, pero, con las dificultades que se presentaban en los últimos años para comercializarlo al extranjero, los agricultores se dieron a la tarea de crear mercados nacionales. Así iniciaron en 1956 una fuerte campaña a través de la prensa para inducir a los connacionales mexicanos a consumir garbanzo (Ayala, 1957, p. 186).

Como señalamos anteriormente, en 1947 la producción fue de 33000 toneladas, destinadas a la exportación, al igual que las de 1948 con igual cantidad. Los problemas se presentaron en 1949 cuando se produjeron 50000 toneladas, que quedaron almacenadas por no encontrar mercados, así se fueron acumulando las siguientes cosechas hasta 1953, cuando volvieron a encontrar destinos de venta (Ayala, 1957, p. 187).

Por tal motivo, y con el apoyo del gobierno estatal y federal, además de organizaciones de agricultores como la Confederación de Asociaciones Agrícolas del Estado de Sinaloa (CAADES) y la Unión Nacional de Productores y Exportadores de Garbanzo (UNPEG), se consiguieron subsidios

\footnotetext{
${ }^{8}$ España era el mercado natural de la producción de garbanzo de Sinaloa debido a la calidad que presentaba el producto cosechado en sus valles, pues competía incluso con el garbanzo cosechado en ese país.
} 
para su exportación y se tomaron medidas para diversificar los mercados, y para convertir el garbanzo en alimento habitual de los mexicanos, cuyo mercado había sido poco explotado.

Mediante la diversificación de los productos que se sumaron a la tradicional producción del garbanzo en el valle del Évora, se fortaleció la economía de la región, haciendo ostensible que Guamúchil se convirtiera en lugar de embarque de la producción por medio de la estación del ferrocarril. Asimismo, en dicha población se inició un proceso de concentración empresarial para la distribución regional de productos y servicios.

\section{Desarrollo empresarial en el Évora: diversificación económica}

A partir de 1940 los empresarios de la región que se habían visto beneficiados de la agricultura empezaron a diversificar sus actividades económicas y a trazarse mejores proyectos de inversión, incursionando en el sector comercial y de servicios. Para esto, muchos de ellos ubicaron su lugar de residencia en Guamúchil y otros más se establecieron en las cercanías de este, entre los municipios de Mocorito y Angostura.

En el ramo económico surgieron agrupaciones como la Cámara de Comercio y la Asociación de Agricultores. ${ }^{9}$ En el caso de la Cámara de Comercio de Guamúchil, ${ }^{10}$ los comerciantes establecidos en esta plaza la constituyeron por acuerdo formal el 1 de junio de $1933 .{ }^{11}$ El objetivo primordial de este tipo de organizaciones era iniciar, estimular y proteger todas las actividades que formaban la vida económica, social y cívica de Guamúchil y la región del río Mocorito (territorio demarcado en los municipios de Mocorito y Angostura). ${ }^{12}$

También surgieron instituciones para auxiliar la banca privada, cuya función era canalizar el crédito en beneficio de la agricultura estatal, como en el caso de la Unión de Crédito Agrícola de Guamúchil, pues de acuerdo

${ }^{9}$ Este tipo de asociaciones eran promovidas por la Secretaría de Economía Nacional y necesitaban su aprobación formal para operar. Es también el caso de las asociaciones de agricultores de las diferentes cuencas del Estado, las cuales se agruparon en la Confederación de Asociaciones Agrícolas del Estado de Sinaloa (CAADES).

${ }^{10}$ De conformidad con la ley para la constitución de Cámaras Nacionales de Comercio del 12 de junio de 1908.

${ }^{11}$ Roberto Macías Fernández, notario público, escritura 125, vol. II, 15 de junio de 1933, Acta Constitutiva de la Cámara Nacional de Comercio de Guamúchil, tomado del Archivo de la Cámara Nacional de Comercio de Guamúchil (en adelante ACANACOG), sin clasificación.

${ }^{12}$ Entre los empresarios fundadores estaban Emilio C. Tisnado, Ángel Lámberri, Evodio de la Vega, Tomás Bayliss, Jesús Díaz, Enrique Bastidas, Valentín Cárdenas, Ángel I. Mariscal, Jesús Manuel Valencia Cárdenas y José G. de León, todos comerciantes establecidos de este lugar, en Roberto Macías Fernández, notario público, escritura 125, vol. II, 15 de junio de 1933, Acta Constitutiva de la Cámara Nacional de Comercio de Guamúchil, en ACANACOG, sin clasificación. 
con la Ley General de Uniones de Crédito, estas surgieron para respaldar al agricultor en el otorgamiento de fianzas y avales; para facilitar la compra de semillas, combustibles y maquinaria agrícola, y auxiliar en la venta de sus productos (Ayala, 1957, pp. 185-186). En el estado funcionaron cinco de ellas, siendo las más importantes las de los Mochis y Culiacán, y menores, de Guasave, Guamúchil y Corerepe.

Los empresarios de la región incursionaron en actividades económicas no sólo de carácter agrícola, ya que sus inversiones fueron canalizadas a proyectos empresariales más diversificados, entre ellos el sector comercial, industrial y financiero (véase cuadro 1).

El lugar de operaciones de sus empresas no se limitó a la región del Évora, pues muchos de estos hombres de negocios se establecieron en la capital del estado (Culiacán), formando sociedades con empresarios de la misma e invirtiendo montos de gran importancia. Los empresarios canalizaban sus inversiones hacia lugares que ofrecían mejores condiciones y menor riesgo, y donde el mercado de consumo era más amplio. La estrategia que muchos establecieron consistía en probar suerte primero en Culiacán, ${ }^{13}$ y después regresar a Guamúchil y así expandirse a otras poblaciones cercanas. Así sucedió con la Unión de Crédito Agrícola de Guamúchil y con el Banco del Noroeste (Ruiz, 1978, p. 50), constituido este último en 1939 también por empresarios de la región.

Otro ejemplo fue el de la Compañía Almacenadora de Sinaloa que de igual forma inició con domicilio en Culiacán, siendo su principal objetivo almacenar, guardar y conservar semillas y en menor medida otras mercancías. Además, las fuentes señalan que también expedía certificados de depósito y bonos de prenda, es decir, se trataba de una organización auxiliar de crédito.

Para finales de la década de 1940 las inversiones realizadas por empresarios de la región comenzaron a diversificarse, incidiendo en la transformación de la fisonomía urbana de Guamúchil. Como ejemplo, la Compañía Cinematográfica del Noroeste, S. A. cuyo objetivo era explotar los negocios cinematográficos y toda clase de espectáculos en la localidad, además de contratar películas para exhibirlas en el territorio de la costa occidental de la república, contratar espectáculos teatrales o celebrar contratos de arrendamiento sobre teatros, salones, etc. (Aguilar y Romo, 2000, pp. 161-162).

Esta misma empresa tenía también el objetivo de levantar un edificio para hotel, cuya construcción inició en 1944. Sin embargo, la edificación

${ }^{13}$ Lo anterior permite explicar que la ciudad de Culiacán era dominante económicamente en la jerarquía de la región y un lugar más atractivo para la inversión en comparación con Guamúchil, que para esta época va a formar parte de su zona de influencia. 


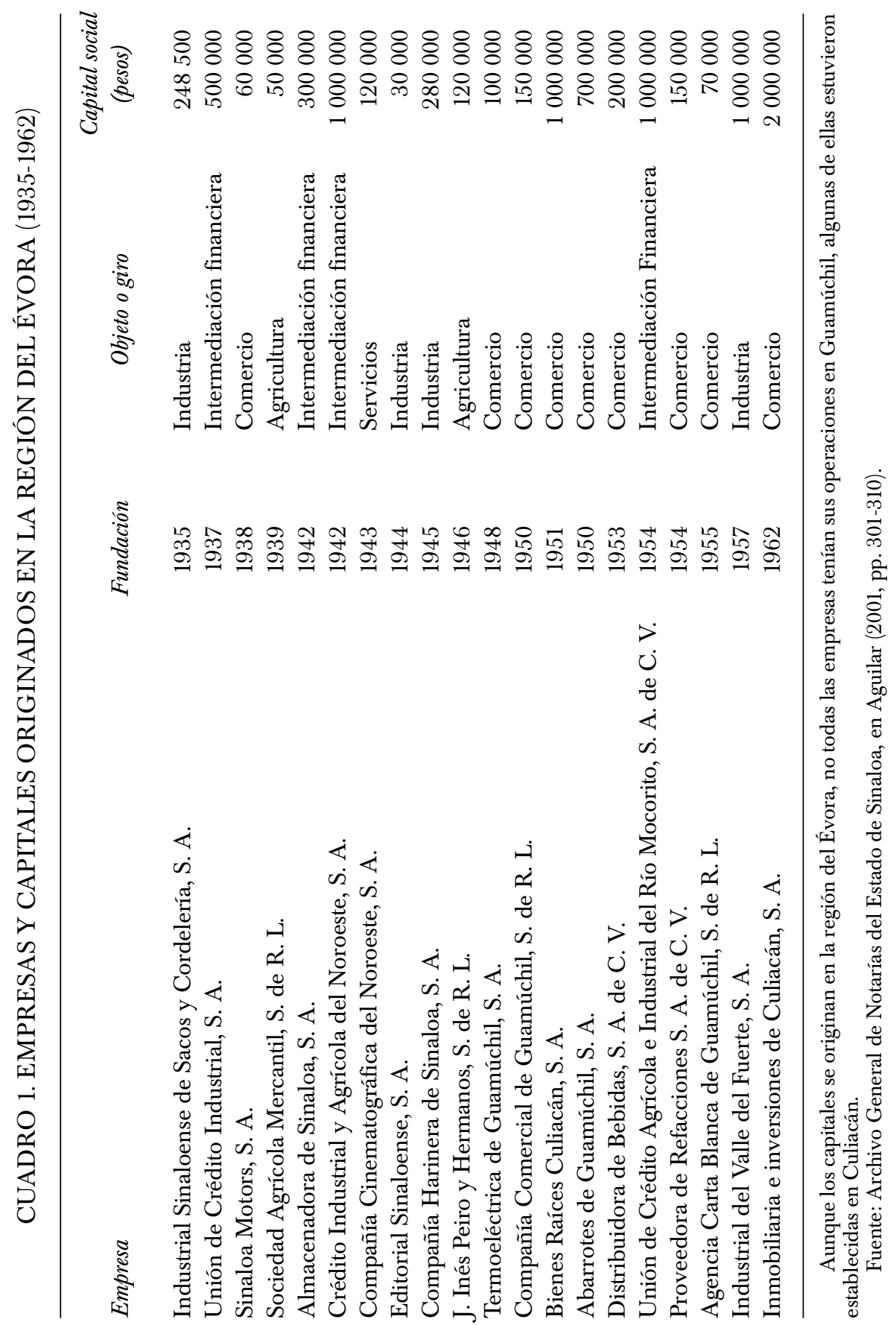


implicaba una obra de mayor inversión respecto a la primera que ya se había realizado, por lo que, tres años después, los accionistas acordaron incrementar el capital a 1000000 de pesos. De este magno proyecto que consistía en cine y hotel, encontramos que este último fue el primero que se inauguró en septiembre de 1947, recibiendo el nombre de Davimar. ${ }^{14}$ El cine se construyó posteriormente al lado del hotel y comenzó a funcionar en 1950. En conjunto, todo el complejo utilizaba un espacio de media manzana, es decir, ocho lotes de primera clase dentro del primer cuadro de la población, justo frente a la plaza (Aguilar y Romo, 2000, p. 162).

Paradójicamente, estas construcciones representaban la modernidad en circunstancias de predominio rural, contrastando con el resto de la población y sus calles que aún permanecían sin pavimentación, pues sólo las grandes ciudades sinaloenses -como Mazatlán y Culiacán- se beneficiaban claramente del erario, destinado a la ampliación y pavimentación de sus principales avenidas (Cruz, 1944).

Este magro crecimiento, que empezaba a vislumbrarse en un sector empresarial en ascenso, precisaba de mejores condiciones para las inversiones, sobre todo para la clase empresarial que se asentaba en el lugar, donde era necesario modernizar el suministro de electricidad. En respuesta a estas carencias "en 1945 se constituyó la denominada Hidroeléctrica de Guasave y Guamúchil, S. A. de C. V., con el propósito de instalar dos plantas termoeléctricas para producir energía eléctrica con fines comerciales e industriales en las poblaciones de Guamúchil, Guasave y Sinaloa” (Aguilar y Romo, 2000, pp. 162-163).

Con esta iniciativa se pretendía transformar el suministro de electricidad de Guamúchil, la cual había sido proporcionada por una empresa menor de Luz y Fuerza. ${ }^{15}$ De acuerdo con Aguilar y Romo (2000), “el servicio de energía eléctrica era sumamente ineficiente y costoso, por lo que un grupo de comerciantes y profesionistas de la ciudad se organizaron y en 1948 constituyeron la sociedad anónima denominada Termoeléctrica de Guamúchil, con la finalidad de establecer una planta generadora de energía eléctrica que cubriera la demanda de servicio en la población” (pp. 164-165).

${ }^{14}$ Según Esqueda (1993) el nombre Davimar que se le dio a este complejo instalado en Guamúchil derivó de las primeras letras de los apellidos de los socios, de la siguiente manera: Da, corresponde a Alfonso Díaz Angulo; Vi, a Cosme Villaverde; Ma, a Patricio MacConegly, y R, a Cristino de Romo (pp. 140-141).

${ }^{15}$ El Ayuntamiento celebró los acuerdos con Francisco Mussot Cañedo para el establecimiento de la empresa suministradora de electricidad Luz y Fuerza, cubriendo tanto los intereses particulares y públicos (alumbrado público) de esta, en Actas de Cabildo, libro 17, foja 139. Archivo Histórico del Municipio e Mocorito (en adelante AHMM). 
Las empresas antes mencionadas responden a un fenómeno de aglomeración empresarial localizado, tomando como soporte espacial un lugar específico. En estos espacios de dimensiones reducidas, no sólo se detectan las grandes y medianas empresas con vastos capitales provenientes en su mayoría de la actividad agrícola, sino también los pequeños negocios que forman parte de un paisaje en procesos de transformación de lo rural a lo urbano.

\section{Guamúchil: pequeña ciudad comercial}

El comercio de Guamúchil desempeñó un papel importante para la economía de la región, así como para su configuración urbana. En este sentido, un elemento importante fue la construcción del mercado municipal en este sitio ${ }^{16}$ donde algunos comerciantes que habían instalado sus negocios en las calles cercanas a la estación pasaron a ocupar un espacio organizado y de concentración comercial. ${ }^{17}$ Además, con la implementación de los vehículos de motor y el uso de transportes de pasaje y carga se construyó una terminal de camiones en el mismo mercado ${ }^{18}$ hecho que permitió mayor movilidad de personas hacia el centro la población.

Para fines de la década de 1950, Guamúchil había adquirido importancia comercial en la región centralizando las actividades de ese sector económico (Directorio agrícola, comercial, industrial y profesional del estado de Sinaloa, 1956, p. 51 ${ }^{19}$ mientras que la agricultura de la zona era la base de su desarrollo, gracias al dinamismo en las zonas agrícolas de los municipios de Guasave y Angostura que empezaron su despegue con el impulso del garbanzo (Ibarra, 1993, p. 74).

${ }^{16}$ Decreto 425 (16 de octubre de 1943). Periódico Oficial del Estado de Sinaloa, núm. 121.

${ }^{17}$ El crecimiento del comercio local provocó que para 1955 los locatarios del mercado municipal se vieran en la necesidad de solicitar una ampliación a dicho espacio comercial. La ampliación se llevó a cabo durante ese mismo año, a lo que se sumó la construcción de la terminal de camiones para pasaje y carga, dentro del mismo mercado, quedando terminada para finales de 1957, en Decreto 233 (1 de septiembre de 1955). Periódico Oficial del Estado de Sinaloa, núm. 101.

${ }^{18}$ El Cabildo de Mocorito autorizó el préstamo a la Unión de Locatarios del Mercado Municipal y Anexos de Guamúchil por la cantidad de 90000 pesos para la construcción de la terminal de camiones de pasaje y carga en la ampliación del mercado, en Decreto 330 (12 de mayo de 1956). Periódico Oficial del Estado de Sinaloa, núm. 53; para su terminación se solicitó una ampliación del crédito por 25000 pesos más, en Decreto 124 (2 de noviembre de 1957). Periódico Oficial del Estado de Sinaloa, núm. 128.

${ }^{19}$ El Departamento Técnico del Estado de Sinaloa (1957) publicó que "el abastecimiento de la población del Estado se efectúa por diferentes centros comerciales, de los cuales destacan por su importancia: Mazatlán, Culiacán, Los Mochis, Guasave, Navolato, Guamúchil, el Rosario y Escuinapa" (p. 51). 
Guamúchil adquirió ventaja en el sector comercial dentro de la región, ya que cubría las necesidades de los habitantes de la zona de influencia. Más tarde fue convirtiéndose también en lugar de carácter administrativo por estar ubicado en el centro de una pequeña región de convergencia de caminos nacionales y vecinales (véase gráfica 1 ).

Su ubicación en el punto de convergencia de vías de comunicación fue un factor que permitió a algunos agricultores y comerciantes avecinarse en este sitio e incursionar en algún tipo de negocio dentro de Guamúchil. Estos atraían la colaboración de contadores y agentes comisionistas, algunos de ellos inmigrantes nacionales y extranjeros, los cuales se colocaban con éxito en nuevos establecimientos comerciales y de servicios, así como despachos de abogados e instituciones de crédito, médicos y maestros que ofrecían servicios de salud y educación en la población (Avendaño, 2008, pp. 24-26).

Una de las principales actividades derivadas del comercio fueron las tiendas de venta al menudeo, conocidos como abarrotes, que representaban 23 de los 86 comercios existentes, es decir, más de la cuarta parte de los negocios. Muchos de ellos se encontraban establecidos en el mercado municipal de Guamúchil, ${ }^{20}$ lugar que para la década de 1950 se había convertido en un espacio central de interacción económica local (Chávez, 2012, p. 139).

El abarrote, como se le denomina en los directorios, pasó a ser el lugar de abastecimiento de productos de todo tipo, sobre todo comestibles y de otros de utilidad cotidiana. Además del mercado municipal, estos se encontraban en distintos puntos del centro de la población y en los barrios, ${ }^{21}$ pues eran los puntos de abastecimiento de productos al consumidor final. También existían otros abarrotes que ofrecían productos al mayoreo, los cuales proveían a los vecinos de las poblaciones rurales que llegaban en sus carretas y vehículos a abastecerse de grandes cantidades de mercancías, pues las visitas a la ciudad no solían ser tan continuas, e implicaban un día entero de camino.

Con el aumento de los vehículos de motor, tanto para uso personal como para el trabajo en el campo, surgió la demanda de productos de refacción y ferretería, que cubrían empresas como Sinaloa Motor's, Com-

${ }^{20} \mathrm{El}$ mercado municipal había permanecido hasta entonces en la zona cercana a la estación como mercado improvisado sobre la calle principal. Según los datos del Archivo Histórico del Municipio de Mocorito, el mercado estaba formado por carpas y se encontraba ubicado cerca de la estación por la calle principal. Para 1942 se empezó a construir el nuevo mercado. Actas de Cabildo, Libro 28, 1943. AHMM.

${ }^{21}$ Existían barrios tradicionales en la época como San Pedro, al otro lado de la vía del ferrocarril; La Loma y La Laguna, hacia el sur; Guamúchil Viejo, hacia el norte, así como algunas rancherías cercanas. 


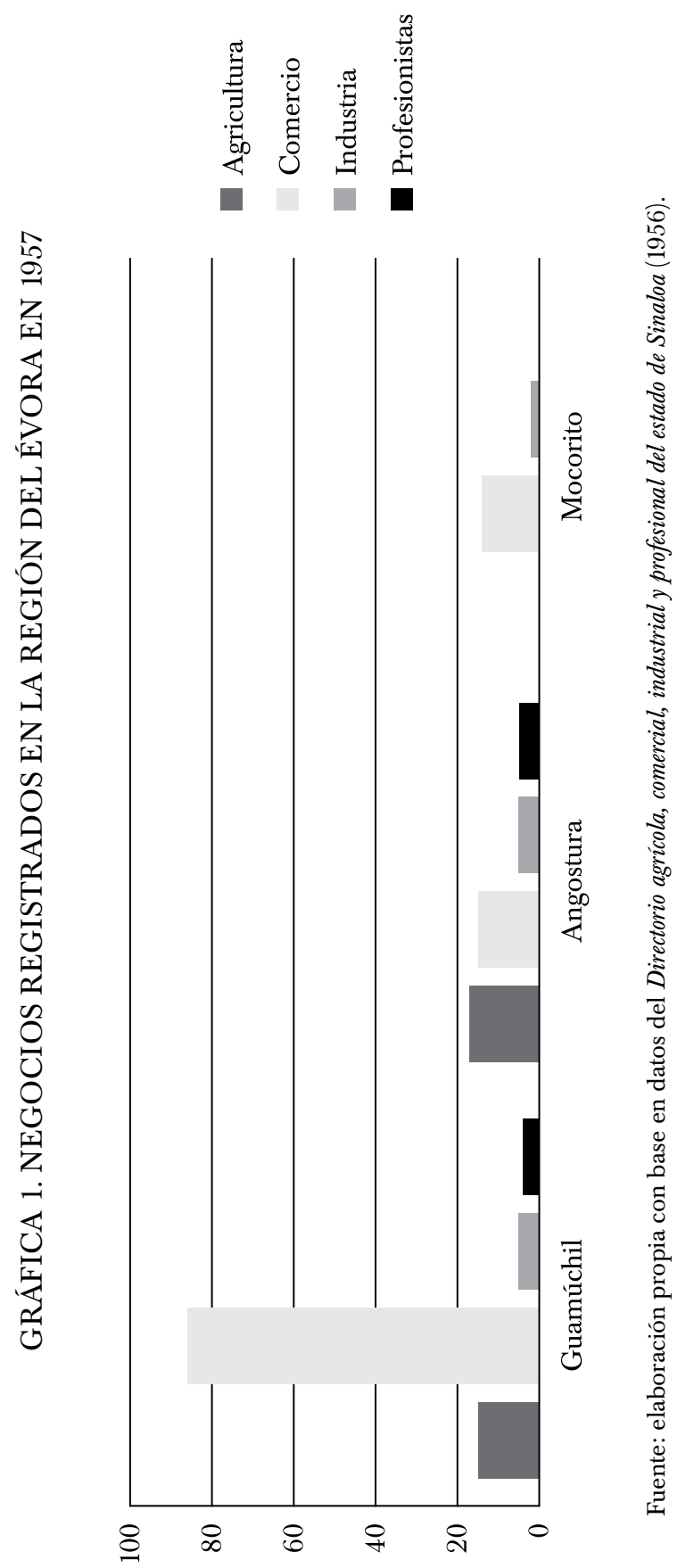


pañía Comercial de Guamúchil, Ferretería Tisnado, Carlos D. Hiser y Ferretera de Guamúchil, así como los negocios de compraventa de semillas e implementos agrícolas. Con la generalización del automóvil y la maquinaria agrícola, las expendedoras de gasolina tuvieron mucha demanda, así como también los talleres mecánicos, de carrocería y pintura ${ }^{22}$ (Avendaño, 2008, pp. 24-26).

Respecto al desarrollo industrial, encontramos que era muy reducido, pues sólo figuraban dos fábricas de hielo, una productora de dulces, una embotelladora de sodas, además de una fábrica de calzado. No obstante lo limitado de la industria local, observamos que la agroindustria de despepite de algodón era una empresa de importancia en la región, no sólo por sus capitales, sino también porque aglomeraba una cantidad significativa de personas empleadas en sus establecimientos (Avendaño, 2008, p. 25).

Este periodo fue un proceso de transición en Guamúchil, ya que después del predominio de la agricultura en las décadas de 1920 y 1930, como impulsor del crecimiento, empiezan a adquirir relevancia el comercio y los servicios; es decir, este lugar se constituyó hacia la segunda mitad del siglo XX como una pequeña ciudad comercial en medio de una región predominantemente agrícola.

\section{POBLACIÓN RURAL Y URBANA EN LA REGIÓN DEL ÉVORA}

En el Sinaloa de la década de 1950 predominaba la población rural, de tal forma que la mayoría de sus habitantes se encontraban en puntos de menos de 2500 habitantes. De acuerdo con los datos que nos presenta Almacenes Nacionales de Depósito (Directorio agrícola, comercial, industrialy profesional del estado de Sinaloa, 1957, p. 57), en este mismo año, del total de la población en el estado $72 \%$ era rural y $28 \%$ urbana. Así, las plazas urbanas por orden de importancia eran Culiacán (con 48936 habitantes), Mazatlán (41 754), Los Mochis (21 552), Escuinapa (9 552), Guasave (8 506), El Rosario (7 624), Navolato (7 133), Costa Rica (6 613), Guamúchil (5 865) y Eldorado (5 124).

Tomando en consideración los datos que arrojaba el censo de 1950, de los diez principales asentamientos de Sinaloa, Guamúchil se consideraba como un centro urbano menor, con una población de más de 5000 habitantes. La situación no cambió sustancialmente para 1960, pues no se presentó un aumento significativo en el número de sus habitantes, cosa que sí

${ }^{22}$ Estos no se encuentran en el registro, aunque formaban parte del panorama comercial de la región y de Guamúchil. 
sucedió en sitios de mayor envergadura establecidos en los valles agrícolas como Culiacán, Los Mochis y Guasave (véase cuadro 2).

A pesar de que en Guamúchil no se percibió un crecimiento significativo para esas décadas, como en otras ciudades del estado, se colocaron las bases para su desarrollo posterior. En este sentido, Garza y Sobrino (1989, p. 22) mencionan que un factor de importancia y cohesión regional e internacional lo constituyó la carretera federal México 15, considerada por los especialistas como el sendero más importante para la vinculación de las ciudades en el estado.

La carretera federal 15 es con mucho la más importante: atraviesa el estado de norte a sur; tiene una extensión de 669 kilómetros; va hacia el norte hasta Nogales pasando por Sonora, hacia el sur a Nayarit y continúa hasta la Ciudad de México. Al interior del estado de Sinaloa atraviesa los municipios de Ahome, Guasave, Salvador Alvarado, Mocorito, Culiacán, Elota, San Ignacio, Mazatlán, El Rosario y Escuinapa. Por sus márgenes se encuentran 63 poblaciones (ocho de las cuales son urbanas) con un número total de 805000 habitantes; es decir, $43.5 \%$ de la población total del estado (Garza y Sobrino, 1989, p. 64).

La interacción e interrelación de Guamúchil con las ciudades que estaban vinculadas por medio de la carretera Internacional, le conferían ciertas ventajas de localización en el orden regional, configurando una ciudad con economía abierta, tanto para adquirir insumos para la producción o productos para el consumo, como para distribuir sus excedentes productivos o la mano de obra emigrante. Por tal razón, los medios de comunicación como el ferrocarril y la (recién construida) carretera iban a desempeñar un papel decisivo para la urbanización de Guamúchil.

Uno de los primeros intentos por regular y planificar los centros urbanos en el estado de Sinaloa se dio en 1941, mediante la promulgación de la Ley de Cooperación, Urbanización, Planeación y Obras Púbicas, bajo el influjo de la primera Ley Federal de Planeación de 1930 y del primer Plan Sexenal de 1934-1940 del Partido Nacional Revolucionario. Esta ley definía la urbanización y planeación como un servicio social-municipal, tratando de dar a la ciudad una fisonomía con sentido estético y armónico, por lo que las poblaciones deberían tomar como base un plano regulador, el cual tenía que ser formulado por consejos directivos y los consejos municipales de urbanización, para ser aprobados en última instancia por la autoridad municipal (Favela, 1992, p. 23).

La aplicación de estas leyes no produjo el efecto deseado sobre Guamúchil, pues presentaba circunstancias particulares como su dependencia política con el municipio de Mocorito, lo que dificultaba la gestión de re- 
Am. Lat. Hist. Econ., año 23, núm. 3, septiembre-diciembre, 2016, pp. 174-203

CUADRO 2. POBLACIONES IMPORTANTES DE SINALOA

COMPARADAS CON LA DE GUAMÚCHIL, 1940-1960

\begin{tabular}{lrrr}
\hline Localidad & 1940 & 1950 & 1960 \\
Culiacán & 22025 & 48936 & 85024 \\
Mazatlán & 32117 & 41754 & 73751 \\
Los Mochis & 12937 & 21522 & 38302 \\
Guasave & 4997 & 8506 & 17510 \\
Guamúchil & 4526 & 5865 & 7878 \\
\hline
\end{tabular}
1964).

Fuentes: Dirección General de Estadística/Secretaría de la Economía Nacional (1948, 1953,

cursos para la urbanización favoreciendo en mayor manera a la cabecera municipal (Mocorito). ${ }^{23}$

En 1950 Guamúchil era un pueblo con carencias en los servicios más elementales, el abastecimiento de luz y agua eran deficientes, pues la planta de energía beneficiaba a una pequeña zona de la población, y operaba de siete de la tarde a once de la noche. Asimismo, el agua entubada llegaba a escasos sectores, por lo que había que llevarla del río por medio de acarreo en barricas en carretas tiradas por fuerza animal (Chávez, 2012, p. 153).

En este contexto, el crecimiento de Guamúchil requería de una parte importante de las cuentas públicas del municipio de Mocorito, pero los recursos no fluían como se quería, pues la vía por la cual se realizaban las solicitudes de recursos era a través de una Junta de Mejoras Materiales, una agrupación tradicional que funcionaba desde el siglo XIX, cuya función era representar a la comunidad ante el municipio en lo concerniente a las necesidades de obras públicas.

Aunque con poca eficiencia y ciertas limitaciones, dicho organismo pudo gestionar recursos para construir en 1940 un edificio en el panteón del lugar, incluso la comuna municipal aprobó un gasto de 2732.92 pesos para limpia, desmonte y embellecimiento en Guamúchil, así como 800 sacos de cemento para obras varias (Avilés, 2010, p. 90).

${ }^{23}$ Guamúchil había superado desde 1930 en población a Mocorito, por lo que existía el temor de que el gobierno del estado optara por trasladar la cabecera municipal a Guamúchil, como ya se había hecho para el caso del municipio de Ahome, que cambió su cabecera municipal a Los Mochis, o el caso de Elota, que había cambiado su cabecera municipal a La Cruz, o en última instancia que formara un nuevo municipio. 
El municipio de Mocorito era el responsable de la urbanización de lugares como Guamúchil, ya que se trataba de una de sus sindicaturas. ${ }^{24}$ Para tal caso, el municipio contaba con un presupuesto de egresos que autorizaba la comuna para cada año, por lo que en 1942 fueron designados 77088.75 pesos divididos en 17 partidas; ${ }^{25}$ de estas, sólo tres se destinaban al mantenimiento y construcción de la obra pública, es decir, un poco más de 15\% del total de los egresos municipales (Avilés, 2010, pp. 96-97).

De lo anterior, sólo una era para las mejoras materiales, representando $7.5 \%$ de los egresos de ese año. Este último porcentaje se encontraba asignado tanto para la cabecera municipal (Mocorito) como para Guamúchil, además de las comunidades menores del municipio que lo requerían, por lo que dicho presupuesto resultaba claramente inoperante para la urbanización de ambas poblaciones.

Aun así, la comuna de Mocorito autorizó para que se ofreciera el servicio de luz pública para las poblaciones de Guamúchil y Mocorito. ${ }^{26}$ Por su parte, los servicios de limpia eran atendidos con dos unidades, una pipa para el riego de las calles y un camión recolector de basura. En este punto, es importante señalar que en el plano de la población se habían establecido callejones de drenaje que cortaban a la mitad cada una de las manzanas que lo componían, ${ }^{27}$ los cuales permanecían subutilizados, pues debido a la deficiencia del servicio de agua y al no contar con servicio de drenaje se anulaba su razón de ser. Por su parte, los habitantes utilizaban fosas sépticas que resolvían el problema de las aguas negras.

Además de la necesidad de servicios urbanos que se presentaban, el crecimiento de la población provocó también la demanda de lotes para construir viviendas. Por tal motivo, en 1946, el municipio de Mocorito llevó a cabo la primera ampliación del plano urbano, al que la comuna se refería como el fundo legal de Guamúchil. Con dicho ensanche se agregaron 173 manzanas a la nueva zona urbana. Fue en el mencionado año cuando

24 La categorización político-administrativa que presentan las poblaciones en el estado de Sinaloa se encuentra jerarquizada desde la capital del estado, los municipios, sindicaturas, comisarías y finalmente las rancherías (sitios de pequeñas dimensiones), véanse los sexto y séptimo censos generales de población (Dirección General de Estadística/Secretaría de la Economía Nacional, 1948 y 1953).

${ }^{25}$ Actas de Cabildo (12 de diciembre de 1941). AHMM.

${ }^{26}$ Actas de Cabildo, libro 17, foja 139. AHMM

${ }^{27}$ Desde la creación del primer plano del pueblo de Guamúchil en 1917, se establecieron manzanas de $70 \times 80$ metros divididos a la mitad por callejones, los cuales fueron proyectados para la construcción de tuberías para agua potable, drenaje y recolección de basura. Aunque en la práctica dichos callejones no tuvieron operatividad planeada, ya que los propietarios de los lotes optaron por dividir sus terrenos, construyendo o vendiendo en la parte del callejón, esto causó en épocas posteriores, que los servicios públicos encarecieran, pues se tenía que construir servicios públicos de agua y drenaje por las calles y también por los callejones. 
"se aprobó el decreto que creaba el nuevo fundo legal de Guamúchil"; ${ }^{28}$ es decir, la ampliación del antiguo plano que se había elaborado en 1917, cuya extensión había sido de 128.26 hectáreas (110 manzanas) y que implicaba una mayor disposición de terreno susceptible al desarrollo urbano. Con tal ampliación, se superaba en más de 150\% la mancha urbana después de casi 30 años (véase mapa 2).

Al llevarse a cabo la transformación del plano de Guamúchil, la autoridad municipal de Mocorito puso a disposición de los habitantes nuevos lotes considerados urbanos. Las personas que tuvieron acceso a la compra de solares buscaron adjudicarse el mayor número de estos, desde cinco hasta quince o 16 lotes por persona, como lo señala el siguiente ejemplo: "El caso del Señor Francisco Vidales, que en el mes de junio de este mismo año de 1946 [...] presenta un escrito que dirige al Ayuntamiento, donde pide se le rebaje un 50\% el valor de los [106] lotes de terreno cuya posesión tienen comprobada en la comunidad de Guamúchil en terrenos de la nueva ampliación del fundo legal" (Avilés, 2010, p. 114).

Con el caso anterior, la comuna tuvo que acceder a la Ley de Presupuesto Municipal donde se especificaba que sólo se podían adquirir 1240 metros cuadrados por familia (cuatro lotes de $31 \times 10$ ), por lo que la petición fue rechazada. Sin embargo, los casos como el ya mencionado se siguieron presentando con frecuencia. Por tal motivo, observamos que en 1956, diez años después de la última ampliación, el Ayuntamiento de Mocorito tuvo que realizar una nueva ampliación del fundo legal de Guamúchil agregando otras 28 manzanas, con lo que llegaba a un total de 311. Lo anterior indica dos cosas: que hubo un crecimiento muy marcado en esta década, o bien, que pudo haber un alto nivel de acaparamiento de lotes, cosa que ya había sucedido en las anteriores ampliaciones del fundo legal, incluso desde su creación. El fenómeno de acaparamiento de lotes desencadenó serios problemas de especulación en la propiedad raíz, con consecuencias de la falta de servicios públicos debido a la enorme cantidad de lotes baldíos y la falta de construcción en esos terrenos potencialmente urbanizables.

\section{LA ZONA URBANA DE GUAMÚCHIL Y SUS VÍNCULOS EN LA REGIÓN DEL ÉVORA}

La disposición y forma del primer cuadro de la ciudad tuvo sus orígenes en 1917, fecha en la que se proyectó el primer plano del pueblo, en una superficie de un kilómetro cuadrado, donde quedaron proyectadas las ca-

${ }^{28}$ Actas de Cabildo, libro 30, 1946, foja 32. Aнмм. 


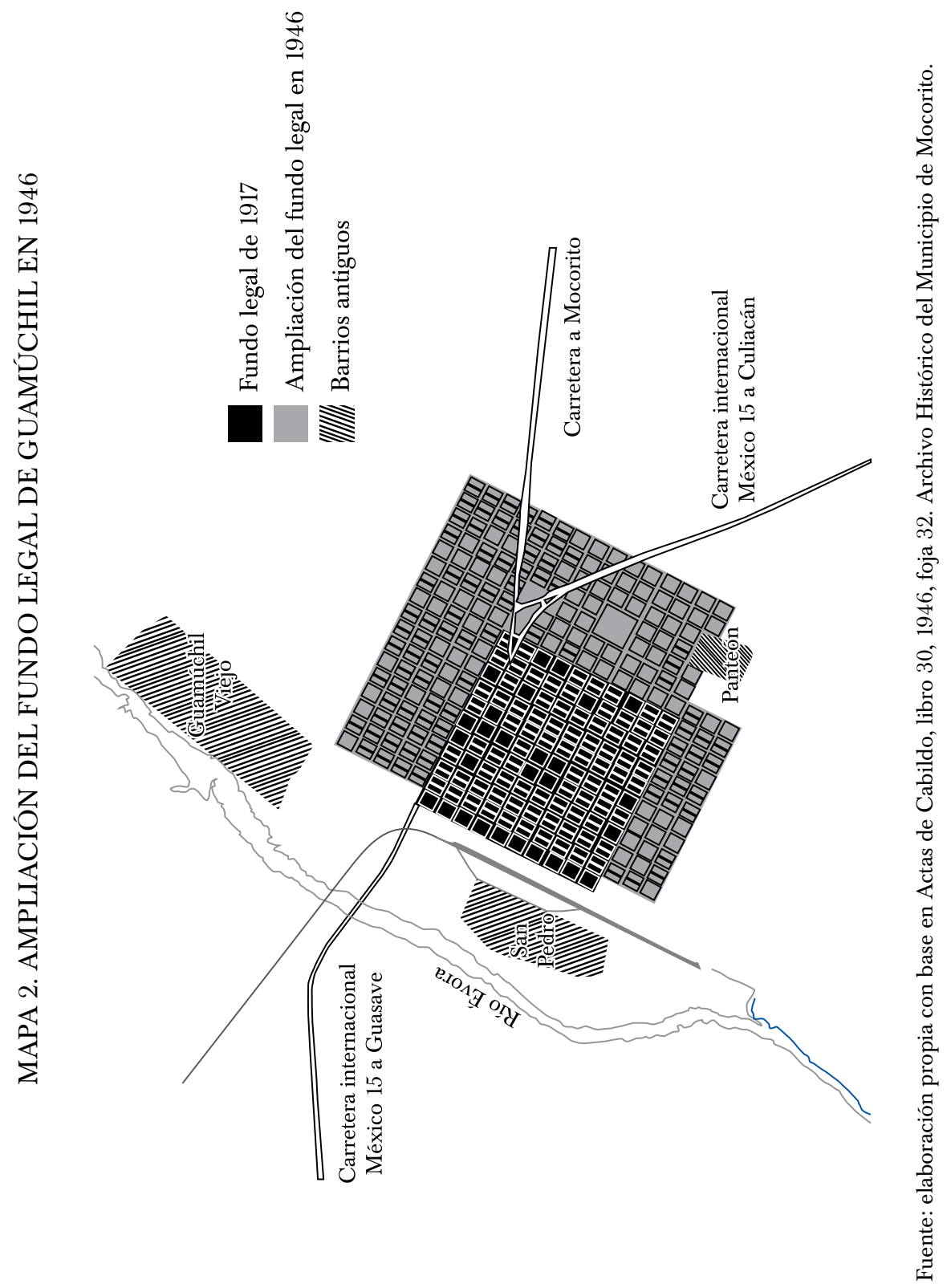


lles y avenidas que configuraron el primer plano urbano de la población. Este primer cuadrado urbano se estableció al lado oriente de la estación y fue denominado Guamúchil Nuevo, con dos barrios cercanos: San Pedro de Guamúchil, ubicado al otro lado de la estación y Guamúchil Viejo, ubicado río arriba. La condición de tales barrios fue quedar excluida de esta primera disposición urbana, pues se dividió la zona planeada estratégicamente de la zona rural, con terrenos de contornos amplios y desprovistos de acceso a los limitados servicios públicos.

El punto de partida para la zona urbana fue la vía del ferrocarril, ya que hacía las veces de eje divisorio del barrio antiguo de San Pedro y de la parte urbana. Paralela a ella, se originó la primera avenida hacia el oriente quedando identificada con el nombre de Ferrocarril, con diez avenidas más hacia dicho sector (Vega, 1985). Las calles que cruzaban las avenidas, en un desplazamiento paralelo de sur a norte fueron nueve, y fue la calle Antonio Rosales la que actuó como eje de las actividades económicas debido a su ubicación frente a la estación de ferrocarril.

De esta manera se estableció el trazo urbano de Guamúchil, que constaba de once avenidas, nueve calles y sus respectivos callejones, con un trazo simétrico que daba al nuevo poblado un aire de ciudad urbana moderna al estilo de las ciudades estadunidenses, al menos en lo que concernía al plano ideal inicial. Conforme pasó el tiempo, Guamúchil absorbió un crecimiento cada vez más notable, por lo cual la ampliación de la zona urbana se desplazó hacia el oriente de la población, con la creación de nuevas calles que se agregaron hacia el norte y el sur.

Desde la zona urbanizada de Guamúchil se originaban una serie de conexiones por medio de diferentes caminos. Longitudinalmente, la carretera federal México 15 cruzaba por el lado norte a la población, como la conexión más importante, y conectaba hacia el sur con la ciudad de Culiacán y hacia el norte con Guasave ${ }^{29}$ y Los Mochis.

La etapa de construcción de la carretera México 15 se caracterizó por el asfaltado de las rúas, iniciado intensamente bajo el gobierno de Rodolfo T. Loaiza, arribando a un mayor nivel a fines de 1940. Casi al término del gobierno de Pablo Macías se combinó la reparación de carreteras con el interés por construir los caminos vecinales que aparecían como condición indispensable para lograr "el total desarrollo de la potencialidad agrícola de Sinaloa” (Macías, 1948; Zavala, 2000, pp. 128-130).

\footnotetext{
${ }^{29}$ Avilés (2010) refiere que para 1940 existía una comisión para construir la carretera entre Guasave y Guamúchil por medio de la Junta de Caminos, a la que se le donaron 3000 pesos para dar inicio a la construcción de la vía que uniría estas dos poblaciones (p. 96), véase también Actas de Cabildo (12 de diciembre de 1941). AмHM.
} 
Los caminos vecinales fueron infraestructura necesaria para vincular diferentes puntos dentro de la región, parte de los ejidos en el valle del Évora se encontraban comunicados por medio de ellos teniendo su origen en Guamúchil. De manera que pasando por los poblados angosturenses llegaban hasta la playa Bahía de Santa María, en la costa del Pacífico. ${ }^{30}$ Existían además otros caminos vecinales que eran numerosos y que unían los poblados cercanos (aunque muchas veces sólo eran veredas). Este sistema de comunicaciones para 1947 aún puede considerarse con deficiencias, pues, aunque se dijera lo contrario en los informes oficiales, en ocasiones se tornaba intransitable especialmente en la época de lluvias.

Sin duda, el mejoramiento y la ampliación de caminos, incluidas las vías de herradura o los nuevos caminos carreteros, fueron signo de modernización y activación de la economía regional que devino de la actividad agrícola en expansión. Para finales de la década de 1950, según datos del Departamento Técnico del Estado de Sinaloa (1957, p. 25) las comunicaciones en la entidad contaban con 1483 kilómetros de caminos, de los cuales 1039 estaban pavimentados, 180.5 revestidos, 148 eran brechas y 115.5 de terracerías. La apertura y, sobre todo, la pavimentación de carreteras, acercó a las ciudades venciendo su tradicional aislamiento (Zavala, 2000, p. 130).

La lógica de construcción de carreteras respondió a la proliferación de los nuevos vehículos de motor a gasolina. Este nuevo medio sustituía las antiguas carretas jaladas por fuerza animal y complementaba al ferrocarril que aún seguía vigente, pero también venía a dar un nuevo aire a las ciudades y a los pueblos, ya que muchas de ellas, como Guamúchil, parecen haber sido planeadas teniendo en consideración el nuevo vehículo, sobre todo por el tamaño tan amplio de sus calles.

Entre 1940 y 1950, debido a las condiciones de crecimiento económico del país, se percibió un incremento notable también en las actividades del estado, debido al desarrollo agrícola e industrial, el cual se reflejó en el aumento de vehículos, registrándose en 1951 la cantidad de 7568 vehículos de motor, es decir, un aumento promedio de 445 por año. En el año de 1955 se registraron 4682 automóviles particulares; 6975 camiones particulares; 1962 automóviles de servicio público, sumando en total 14214 vehículos (Departamento Técnico del Estado de Sinaloa, 1957, p. 25). ${ }^{31}$ Debido al desarrollo de la región y la construcción de nuevos caminos, el aumento de vehículos continuó creciendo, especialmente en la década de (AHA)

${ }^{30}$ Aprovechamiento Superficial, caja 998, exp. 14033, fs. 4-5. Archivo Histórico del Agua

${ }^{31}$ Según el Departamento Técnico del estado de Sinaloa (1957) para este mismo año y calculando una población de Sinaloa de 632500 habitantes, existía una relación aproximada de 84 habitantes por vehículo (p. 25). 
1960, que representó un nuevo periodo de urbanización de las ciudades en Sinaloa.

La construcción de caminos vecinales fue de gran relevancia, pues su aparición significó la unión de muchas comunidades que anteriormente habían permanecido incomunicadas. En 1954, la Secretaría de Comunicaciones planteaba que en Sinaloa se hacía indispensable una red de caminos vecinales que permitiera un óptimo aprovechamiento de los recursos del estado y una mejor utilización de las carreteras troncales, de los ferrocarriles y de las comunicaciones marítimas; por tanto, dividió en tres categorías los caminos vecinales que cruzaban Sinaloa: de primera, es decir, aquellos que aparecían como caminos pavimentados; de segunda, como caminos revestidos, y los de tercera o de penetración, cuyos caminos únicamente contaban con un carril y con revestimiento económico (véase cuadro 3).

Las conexiones más importantes de estos caminos fueron los que conformaba el circuito Angostura-Guamúchil-Mocorito, de los que sólo se consideraba como de primera categoría el de Mocorito-Guamúchil. Empero, el camino que conectaba a Guamúchil con Angostura, que también representaba importancia en la región por establecer el vínculo principal con la zona agrícola, era considerado de segunda. Por su parte, los caminos de tercera, que eran denominados "de penetración", fueron los de menor importancia, ya que conectaban los lugares más alejados, representando los caminos con mayor problema de acceso en la región (Ayala, 1957, p. 100-102).

La modernización de la carretera federal fue clave en la década de 1950, pues agilizó el traslado de personas y mercancías, además de que se complementó con los caminos transversales que conectaban, por un lado, a Mocorito hacia los altos y a Angostura en la zona del valle y el litoral, creando una red de caminos menores que unían a los poblados de la región.

\section{Centralidad REgional EN El ÉVORA}

En cuanto a la región del Évora, la zona de influencia quedó delimitada por el sistema de poblados vinculados por dichos caminos, donde Guamúchil representaba la de mayores dimensiones. A esta última fluían los productores para vender sus mercancías, así como los consumidores que buscaban bienes o servicios, pues, en teoría, los individuos confluyen al lugar más cercano que ofrezca las mayores ventajas.

Tanto Angostura como Mocorito representaban puntos de importancia regional, como cabeceras de sus respectivos municipios. Sin embargo, los habitantes de los pequeños pueblos iban directamente a la ciudad que concentraba mayor cantidad de negocios de venta de productos o servicios. 
CUADRO 3. CAMINOS VECINALES EN LA REGIÓN DEL ÉVORA, 1954

\begin{tabular}{llc}
\hline Camino & \multicolumn{1}{c}{ Categoría } & $\begin{array}{c}\text { Extensión } \\
\text { (kilómetros) }\end{array}$ \\
Mocorito-Guamúchil & Primera & 16 \\
Playón-Angostura-Guamúchil & Segunda & 23 \\
El Valle-Mocorito & Segunda & 15 \\
Bacubirito-El Valle & Segunda & 25 \\
Sinaloa-Agua Escondida-Ciénega-Guamúchil & Segunda & 68 \\
Los Hornos-El Padre-Bacubirito & De penetración & 44 \\
Mocorito-San Benito-Badiraguato & De penetración & 41.5 \\
\hline
\end{tabular}

Fuente: elaboración propia con base en Ayala (1957, pp. 100-102).

La concentración de los bienes y servicios en Guamúchil tuvo correspondencia con su crecimiento demográfico, ya que superó en número de habitantes a las demás poblaciones del espacio regional. Para explicarlo, nos remitimos a la década de 1930, cuando Guamúchil y Mocorito poseían una población muy similar, 3042 y 2561 habitantes, respectivamente (Dirección General de Estadística/Secretaría de la Economía Nacional, 1935). Sin embargo, para 1940, la situación demográfica se modificó, pues Guamúchil incrementó su población a 4526 habitantes, mientras que en Mocorito disminuyó a 2 357, y otras de importancia como Angostura, que manifestó un incremento poco significativo, ya que de 969 habitantes que tenía en 1930 pasó a 1241 para 1940 , continuando en las décadas posteriores con poco crecimiento (Dirección General de Estadística/Secretaría de la Economía Nacional, 1948).

En la gráfica 2 se observa un constante aumento demográfico en Guamúchil, cosa contraria de lo que se presentó en Mocorito, cuya población decreció a partir de la década de 1930, con un repunte al final de los sesenta. Mientras tanto, Angostura presenta un ligero crecimiento, permaneciendo casi inmóvil durante las tres décadas, lo que indica que la cabecera municipal no era un lugar de atracción para los habitantes de la región.

En la jerarquización de las ciudades del estado, Culiacán y Mazatlán eran las ciudades de mayor influencia, pues sus centros actuaban como vínculos con las ciudades de mayor rango hacia el centro del país. Los centros urbanos de tamaño medio se encontraban en el norte, con distancias de aproximadamente 50 kilómetros, entre ellas Los Mochis, Guasave y Guamúchil. Estas ciudades, a su vez, constituyeron un sistema de ciudades pequeñas que también ejercían atracción sobre sus respectivas zonas de influencia. 


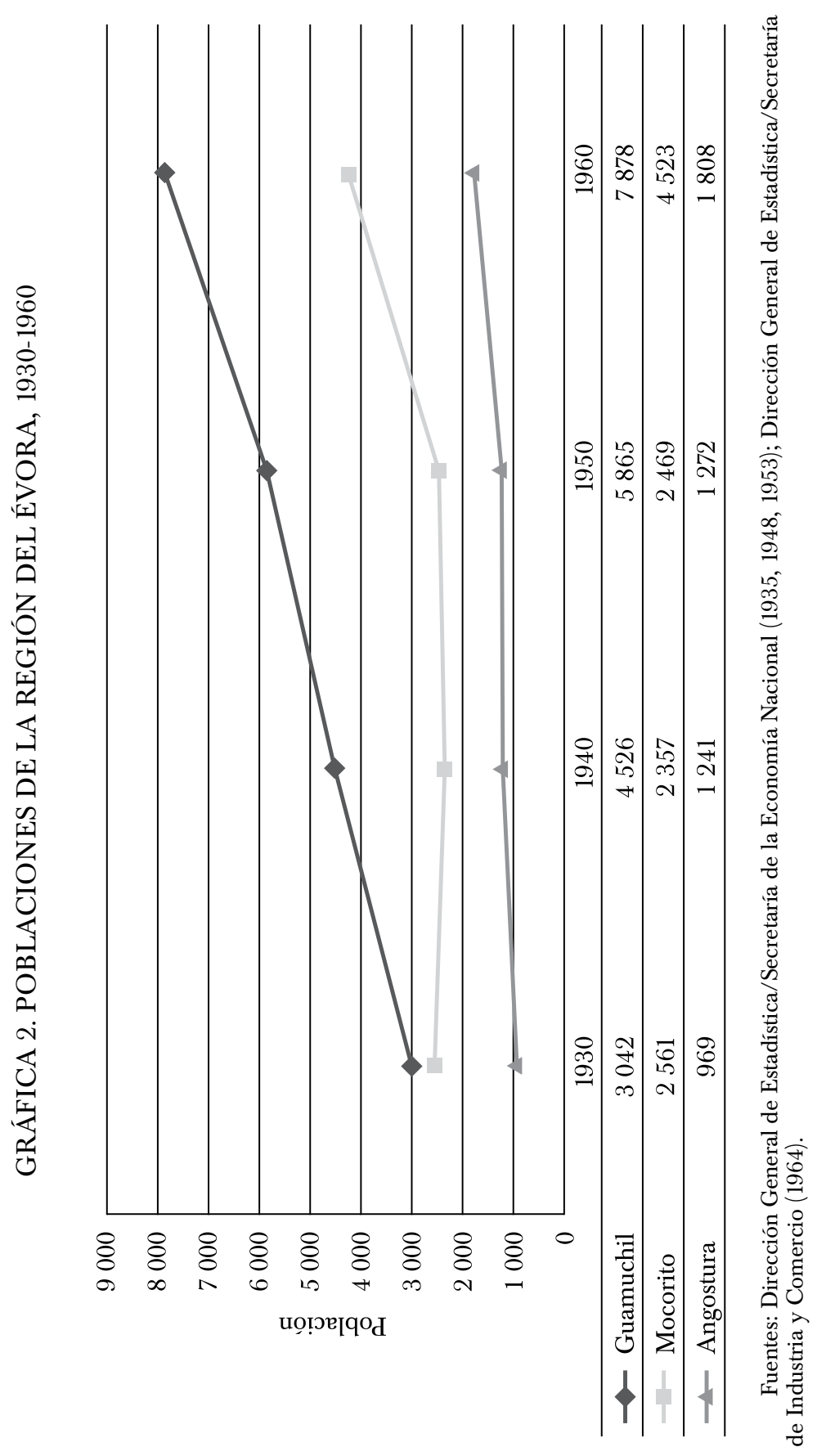




\section{CONCLUSIÓN}

Las regiones más favorecidas en cuanto a desarrollo en este periodo fueron Culiacán y el valle de El Fuerte, mientras que las zonas intermedias, como la del Évora y Guasave aguardaron por inversiones para la modernización del riego y apertura de tierras. Esto explica por qué las ciudades mayores presentan un desarrollo anticipado a las de menores dimensiones, pues sus entornos regionales fueron favorecidos por la construcción de grandes obras de irrigación (presas y canales), así como construcción de nuevos caminos.

Sin embargo, para la mitad del siglo xx, la carretera internacional y la construcción de caminos transversales en la región fue un elemento esencial que dinamizó la actividad comercial, la cual dio pie al desarrollo de la economía local en Guamúchil. Mediante estas vías inició la vinculación entre las poblaciones aledañas con la pequeña ciudad, lo que produjo una incipiente especialización de la ciudad de Guamúchil en el sector comercial y de servicios. A partir de la modernización de las vías de comunicación los lugares, como el estudiado, lograron ganar protagonismo económico y demográfico en el estado.

A pesar de lo que se mencionó anteriormente, Guamúchil creció a ritmo lento, sin alcanzar los 10000 habitantes para la mitad del siglo Xx, lo que indica que el proceso de urbanización fue también lento. Este tipo de poblaciones ejercían un nivel de atracción menor para quien decidía emigrar de manera permanente del campo a una ciudad de mayor envergadura. Sin embargo y pese a la urbanización incipiente, se puede comprobar que sí representó un punto relevante para el intercambio de bienes y servicios regional.

Asimismo, con el crecimiento local y los cambios que se presentaban en España desde finales de la década de 1930, provocaron el cierre de mercados para el garbanzo; por tanto, los agricultores de la región se vieron forzados a diversificar sus cultivos: Por esta razón, el patrón agrícola que había predominado desde inicios de la década de 1920 experimentó un periodo de estancamiento, lo que promovió alternativas distintas en los cultivos y en ocasiones nuevas opciones para la inversión de capitales. Algunos agricultores que tradicionalmente habían permanecido en la actividad optaron por emprender otro tipo de negocios, incursionando sobre todo en el sector comercial local y estatal. Lo anterior también constituyó parte de la transformación de la ciudad, así como la construcción de edificios para los establecimientos comerciales, la ampliación de la zona urbana, el mejoramiento de los caminos y la nomenclatura de las calles.

Además, la utilización del ferrocarril había mantenido importancia para la comercialización de los diversos productos que se embarcaban 
en la estación, mismos que se complementaron con los nuevos medios de transporte que empezaron a cobrar auge en el periodo estudiado. De esta manera encontramos que el transporte de carga y pasaje configuró un nuevo punto de interacción en la ciudad, pues los habitantes de la región circundante, los pueblos cercanos de los altos y de la zona del litoral, así como de los valles, tenían mejor acceso a la ciudad y con ello mayor diversidad de productos y servicios que cubrían sus necesidades. Por tal razón, el espacio que había sido designado como plaza y edificios públicos pasaron a ser ocupados por un mercado municipal y una terminal de autobuses y camiones de carga, por lo que el movimiento comercial se amplió desde la estación hacia la plaza y el mercado, dando un aspecto diferente a Guamúchil.

\section{LISTA DE REFERENCIAS}

Aguilar, G. (2001). Banca y desarrollo en Sinaloa, 1910-1994. México: Universidad Autónoma de Sinaloa/Plaza y Valdés/Dirección de Investigación y Fomento de la Cultura Regional.

Aguilar, G. y Romo, S. (2000). Cristino C. Romo: destacado empresario de la región del Évora. En G. Aguilar G. et al. (coords.), Marginalidad y minorías en el pasado mexicano. México: Universidad Autónoma de Sinaloa/Ayuntamiento de Mocorito.

Aguilar, H. y Meyer, L. (1997). A la sombra de la revolución mexicana. México: Cal y Arena.

Avendaño, A. (febrero, 2008). Pequeños comerciantes. El Debate (Suplemento especial Centenario), 24-26.

AviLÉs, J. S. (2002). Gobernantes de Mocorito, 1871-1926. México: Colegio de Bachilleres del Estado de Sinaloa.

Avilés, J. S. (2010). Mocorito. México: Colegio de Bachilleres del Estado de Sinaloa/La Crónica de Culiacán/Comisión Estatal de los Festejos 2010 en Sinaloa/La Crónica de Sinaloa/Municipio de Mocorito.

Ayala, R. (1957). Sinaloa en los destinos de México. México: Unión Gráfica.

Berman, M. (1988). Todo lo sólido se desvanece en el aire. México: Siglo XXI.

CARrillo, A. (2013). Agua, agricultura y agroindustria. Sinaloa en el siglo XX, México: Universidad Autónoma de Sinaloa/Universidad Autónoma de Nuevo León.

Chávez, J. R. (2012). Guamúchil: la historia de un pueblo (1907-1962). México: Colegio de Bachilleres del Estado de Sinaloa.

Christaller, W. (1966). Central places in southern Germany. Nueva Jersey: Prentice-Hall. Cruz, T. (1944). Informe de gobierno del estado de Sinaloa. México: Gobierno de Sinaloa. Departamento Técnico del Estado de Sinaloa (1957). Esquema social y económico. México: Almacenes Nacionales de Depósito. 
Dirección General de Estadística/Secretaría de la Economía Nacional (1935).

V Censo General de Población. Estado de Sinaloa. México: Autor.

Dirección General de Estadística/Secretaría de la Economía Nacional (1948).

VI Censo General de Población. Estado de Sinaloa. México: Autor.

Dirección General de Estadística/Secretaría de la Economía Nacional (1953).

VII Censo General de Población. Estado de Sinaloa. México: Autor.

Dirección General de Estadística/Secretaría de Industria y Comercio (1964).

VIII Censo General de Población. Estado de Sinaloa. México: Autor.

Directorio agrícola, comercial, industrial y profesional del estado de Sinaloa (1956). Culiacán:

El Diario de Sinaloa.

Esqueda, C. (1993). Crónicas de Guamúchil. Culiacán: Brechas.

FAVEla, P. P. (1992). Antecedentes normativos de planeación urbanística en Sinaloa.

En Desarrollo urbano en Sinaloa, 1987-1992 (pp. 21-32). México: Gobierno del Estado de Sinaloa/Secretaría de Planeación y Desarrollo.

Garrocho, C. (2012). Estructura funcional de las ciudades de México. México: El Colegio

Mexiquense/Consejo Nacional de Población/Fondo de Población de las Naciones Unidas.

Garza, G. (2003). La urbanización de México en el siglo XX. México: El Colegio de México.

GARZA, G. y Sobrino, J. (1989). Industrialización, periférica en el sistema de ciudades de Sinaloa. México: El Colegio de México.

IbARRA, G. (1993). Sinaloa: tres siglos de economía. México: Dirección de Investigación y Fomento de la Cultura Regional.

Marín, A. y Morales, J. J. (2010). Modernidad y modernización en América Latina: una aventura inacabada. Nómadas. Revista Crítica de Ciencias Sociales y Jurídicas, $26(2)$.

MORALES, F. (2007). Impacto de la biotecnología en la formación de redes institucionales en el sector hortofrutícola de Sinaloa, México (Tesis doctoral). Universidad de Barcelona, España.

Macías, P. E. (1948). Informe de gobierno del estado de Sinaloa. México: Gobierno de Sinaloa.

RuIZ, E. (diciembre, 1978). Entrevista con Cristino Romo. Presagio, 18, 49-51.

VegA, A. (1985). El fundo legal y los nombres de las calles de Guamúchil. [Apuntes]. Archivo privado de Arturo Avendaño Gutiérrez, propiedad de la familia Avendaño Ahumada.

Zamudio, R. E. (2009). Historia del desarrollo hidroeconómico de Sinaloa (1947-1970), el caso de la presa Humaya y la Unidad IV del Distrito de Riego 10 (Tesis de maestría). Universidad Autónoma de Sinaloa, Culiacán.

Zavala, A. (2000). Sinaloa: entre el muchacho alegre y las hojas de hierba (buena), 19401950. Culiacán: Colegio de Bachilleres del Estado de Sinaloa. 
Am. Lat. Hist. Econ., año 23, núm. 3, septiembre-diciembre, 2016, pp. 174-203

\section{OTRAS FUENTES}

\section{Hemerografia}

Diario Oficial del Estado de Sinaloa, Sinaloa, México.

El Diario de Sinaloa, Sinaloa, México.

El Regional, Sinaloa, México.

\section{Archivos}

AHmm Archivo Histórico del Municipio de Mocorito, Sinaloa, México.

AHA Archivo Histórico del Agua, Ciudad de México.

ACANACOG Archivo de la Cámara Nacional de Comercio de Guamúchil, Sinaloa, México. 